\title{
3 Research Soure \\ Comparison of Time Management Ability Between Medical Students Who Entered Medical Universities Through Different Approaches
}

Haw-Yaw Shy

National Changhua University of Education

Ching-Yun Chiu

China Medical University

Ming-Wei Chiang

China Medical University

Shih-Chieh Liao (D liaosjay@yahoo.com )

China Medical University https://orcid.org/0000-0001-5335-6957

Research article

Keywords: Comparison, Time Management, Ability, Medical Students, Medical Universities, Approaches, Taiwan

Posted Date: June 24th, 2021

DOl: https://doi.org/10.21203/rs.3.rs-642312/v1

License: (9) This work is licensed under a Creative Commons Attribution 4.0 International License.

Read Full License 


\section{Abstract}

Background: Approaches to admission into medical schools in Taiwan are diverse but primarily involve the Multi-Star Project (MSP), General Scholastic Ability Test (GSAT), and Advanced Subject Tests (ASTs). This study aimed to investigate the differences in time management ability between students admitted into medical schools through different approaches.

Methods: The Time Management Disposition Inventory was employed in a questionnaire survey on 390 students from the 1st to 4 th years of the School of Medicine at China Medical University to investigate their time management ability.

Results: The valid response rate was $100 \%$. According to factor analysis results, the items in the original questionnaire were divided into 3 factors. The total eigenvalue was 14.15; the total variance of the 3 factors was $90.1 \%$ and the Cronbach's $a=0.934$. According to the between-group comparison results, the MSP (adjusted mean = 3.924), GSAT (adjusted mean = 3.729), and AST (adjusted mean = 3.802) groups differed significantly only in their sense of time efficacy.

Conclusions: Approaches of admission into universities profoundly affect medical students' time management ability. Admission through MSP requires exceptional academic performance in 3-year high schools; therefore, the MSP group exhibited the highest sense of time efficacy out of all 3 groups. This enabled those students to effectively plan their short- and long-term learning and perform self-learning at all times. Admission through the GSAT or ASTs solely emphasizes one-time college entrance examination scores. Therefore, those students exhibited a relatively high sense of time value, which enabled them to achieve satisfactory performance in college entrance examinations.

\section{Background}

Time management ability refers to an individual's ability to appropriately use, arrange, and master time. ${ }^{1,2}$ Time management refers to individuals' planning and arrangement of time to use and manage it in a highly efficient and scientific manner, thereby preventing time wasting and improving their work effectiveness. Time management requires people to change their passive time use behaviors and begin actively allocating their time in a systematic, centralized, planned, and purposeful manner, thereby enabling themselves to perform efficient and creative activities. Time management requires people to persistently and purposefully apply reliable job skills to guide and manage their personal daily living and utilize their available time in a reasonable and effective manner. In general, time management can be defined as the act of applying available time in a planned, purposeful, efficient, and reasonable manner to perform creative activities. ${ }^{3}$

At school, students manage their time through self-restraint and the planning of their long-and short-term learning and personal goals, which constitute self-demand and self-expectation. ${ }^{4}$ Time management ability encompasses numerous dimensions, such as concepts on the value of time, demand for selfrestraint, and the formulation and execution of plans. Generally, academic time management refers to 
students' effective and purposeful use of time for their learning goals, which enables them to improve their learning outcomes related to major education goals within a limited amount of time. ${ }^{5}$ Time management ability also influences medical students tremendously; satisfactory time management ability improves students' academic performance, ${ }^{1,6-11}$ work, ${ }^{12}$ and health. ${ }^{2,13}$

The basis of successful medical education lies in selecting medical students suitable for academic schools of medicine as well as ensuring they successfully complete medical and clinical learning and acquire core competencies. The selection of appropriate students is crucial for medical education; in addition to knowledge, students suitable for medical schools and professions must possess specific personality traits and attitudes, including lifelong active learning, self-discipline, altruism, adaptability, and compassion. ${ }^{14-16}$ These personality traits and attitudes cannot be assessed using written tests. ${ }^{17,18}$ When recruiting medical students, medical school authorities must pay attention to their personality traits and attitudes in addition to their knowledge. Therefore, in addition to assessing student candidates' school and entrance examination results, admission supervisors must examine their self-statement and letters of recommendation to determine their eligibility to study in the school. ${ }^{19}$

In Taiwan, approaches of admission into schools of medicine are diverse but primarily involve the General Scholastic Ability Test (GSAT), the Multi-Star Project (MSP), and Advanced Subject Tests (ASTs). Participation in the GAST in January and February is required for admissions through the GAST and MSP each year. GSAT scores are the sole factor determining whether students admitted to schools of medicine through the GSAT can enter the second-stage examination for personal admission applications, which involve written reviews, oral examinations, and school-defined written examinations. Students admitted through the MSP must have their academic results in their 10th-12th grades taken into consideration, whereas students admitted through ASTs rely on their AST scores in July after graduating from high school. ${ }^{20,21}$

Students admitted into schools of medicine in Taiwan through the MSP typically have relatively poor GSAT scores. However, according to numerous studies on students admitted through diverse approaches in Taiwan, those admitted through the MSP-even those with poor GSAT grades-have performed as satisfactorily as those admitted through the GSAT and ASTs; furthermore, most have maintained their standing in the school among the first $50 \% .22,23$

Through the MSP, the primary indicator for admission is candidates' grades during the 3rd year of high school rather than their one-time college entrance examination scores. Therefore, while striking an optimal balance between long-term, sustained academic performance and student life, students must perform in the top $1-3 \%$ in high school through satisfactory and stable learning habits ${ }^{6}$ and self-adjusted learning ability. Research has focused on the relationship between medical students' approaches to admission and their learning performance. ${ }^{22-24}$ This study focused on 1 st to 4 th year students in the School of Medicine at China Medical University, Taiwan, to explore the relationships between medical students admitted through different approaches and their time management ability. 


\section{Method}

\section{Participants}

A questionnaire survey was conducted on 390 students from the 1st to 4th years of the School of Medicine at China Medical University to examine their time management ability. The valid response rate was $100 \%$.

\section{Questionnaire development}

The research instrument employed in this study was the Time Management Disposition Inventory, ${ }^{25}$ the theoretical basis of which is the Time Management Questionnaire by Britton and Tesser ${ }^{13}$ and the Time Management Behavior Scale by Macan. ${ }^{1}$ Students' time management is divided into 3 parts, and accordingly, the time management disposition inventory features 3 dimensions: the sense of time control, which involves knowing the order of priorities, making reasonable plans, setting short-term and long-term goals, and self-reflection; the sense of time efficacy, which requires ability to assess the importance of tasks and allocate time and priorities to them accordingly; and the sense of time value, which indicates sense of the values and importance of time. ${ }^{25}$

The original questionnaire used simplified Chinese characters. Because Taiwanese medical students typically read and write using traditional Chinese characters, the questionnaire was translated from simplified to traditional Chinese. A pretest was conducted in which the answers by 10 third-year students from another school of medicine were examined, and the content and structural validity of the questionnaire were evaluated through factor analysis. A 5-point Likert scale was adopted ( $1=$ "strongly disagree" to 5 = "strongly agree").

\section{Results}

\section{Participant's properties}

The sample consisted of 91 first-year students (23.33\%), 97 second-year students (24.87\%), 96 third-year students (24.62\%), and 106 fourth-year students (27.18\%). Of all the samples, 54 (13.85\%), 230 (58.97\%), and $106(27.18 \%)$ were admitted through the MSP, GSAT, and ASTs, respectively (Table 1).

\section{Table 1. Demographic Data for All Participants in the Courses}

\section{Results of factor analysis}

According to the results of factor analysis on the 44 questionnaire items, items with unsatisfactory reliability and validity were eliminated, reducing the number to 33 (Cronbach's $a=0.934$ ), which were associated with 3 factors. According to the eigenvalues calculated using a reduced correlation matrix, the 3 factors were sense of time control (11 items, eigenvalue $=10.351$, variance $=65.86 \%$, Cronbach's $a=$ 


\begin{tabular}{|lllll|}
\hline Grade & $\begin{array}{l}\text { Multi-star } \\
\text { project }\end{array}$ & $\begin{array}{l}\text { General scholastic ability } \\
\text { test }\end{array}$ & $\begin{array}{l}\text { Advanced subjects } \\
\text { test }\end{array}$ & Total \\
\hline Freshman & 15 & 60 & 16 & $91(23.3 \%)$ \\
\hline Sophomore & 14 & 66 & 17 & $97(24.9 \%)$ \\
\hline Junior & 13 & 54 & 29 & $96(24.6 \%)$ \\
\hline Senior & 12 & 50 & 44 & $106(27.2 \%)$ \\
\hline & $54(13.8 \%)$ & $230(59.0 \%)$ & $106(27.2 \%)$ & $390(100.0 \%)$ \\
\hline
\end{tabular}

0.897 ), sense of time efficacy ( 15 items, eigenvalue $=2.370$, variance $=15.08 \%$, Cronbach's $a=0.901$ ), and sense of time value $(7$ items, eigenvalue $=1.433$, variance $=9.12 \%$, Cronbach's $a=0.805)$. The total eigenvalue of the 3 factors was 14.15, and their total variance was $90.1 \%$ (Table 2). This study's factor analysis results were consistent with those of the dimensions of time management incorporated in the original questionnaire. ${ }^{25}$

Table 2. The Results of Promax SMC Analysis to Verify Three Domains $(n=390)$ 


\begin{tabular}{|c|c|c|c|c|}
\hline TMa1 & Formed goals for each week & 76 & 37 & 14 \\
\hline TMa2 & Defined learning goals for each day & 66 & 43 & 19 \\
\hline TMa3 & Formed goals at the beginning of each year & 61 & 25 & 24 \\
\hline TMb1 & Formed plans for each week & 80 & 42 & 18 \\
\hline TMb2 & Formed learning plans for each semester & 74 & 44 & 21 \\
\hline TMb3 & Formed a schedule for each day & 71 & 35 & 17 \\
\hline TMb4 & Always kept short- and long-term plans & 64 & 52 & 18 \\
\hline TMd1 & Frequently summarized the use of time & 66 & 44 & 33 \\
\hline TMd2 & Frequently acquired knowledge on using time & 59 & 34 & 27 \\
\hline TMd3 & Always assessed yourself according to your goals & 61 & 54 & 26 \\
\hline TMd4 & Frequently shared experience of using time & 52 & 34 & 22 \\
\hline TCMc1 & Assessed the importance and priorities of multiple tasks & 24 & 64 & 31 \\
\hline TCMc2 & Prioritized learning tasks according to their importance & 33 & 66 & 35 \\
\hline TCMc3 & Prioritized important tasks & 47 & 62 & 28 \\
\hline TCMc4 & $\begin{array}{l}\text { Focused on important tasks during times of high work } \\
\text { efficiency }\end{array}$ & 41 & 52 & 18 \\
\hline TCMe1 & Effectively handled numerous tasks & 50 & 67 & 24 \\
\hline TCMe2 & Allocated time to important tasks & 18 & 68 & 47 \\
\hline TCMe3 & Had ideas regarding learning and recreational time & 52 & 61 & 29 \\
\hline TCMe4 & Spent a large amount of time on important tasks & 49 & 52 & 26 \\
\hline TCa1 & Arranged the priority order of tasks reasonably & 42 & 71 & 33 \\
\hline TCa2 & Arranged learning schedules reasonably & 48 & 64 & 28 \\
\hline TCa3 & Allocated learning and activity time effectively & 46 & 60 & 21 \\
\hline TCb1 & Used time effectively & 61 & 65 & 22 \\
\hline TCb2 & Could control most of their time & 35 & 59 & 32 \\
\hline TCb3 & Effectively used class hours & 49 & 52 & 20 \\
\hline TCb4 & Could manage time effectively & 21 & 52 & 45 \\
\hline TVv1 & Time is the most precious thing in the world & 16 & 25 & 69 \\
\hline
\end{tabular}




\begin{tabular}{|clccc|}
\hline TVv2 & Time is life & 18 & 33 & $\mathbf{6 6}$ \\
\hline TVv3 & Time is power & 25 & 35 & $\mathbf{7 1}$ \\
\hline TVv4 & Time is money & 19 & 32 & $\mathbf{5 8}$ \\
\hline TVv5 & Time is benefits & 21 & 34 & $\mathbf{5 7}$ \\
\hline TVv6 & Time is everything & 25 & 26 & $\mathbf{5 4}$ \\
\hline TVv7 & Making good use of time is significance & 39 & 50 & $\mathbf{5 1}$ \\
\hline & Cronbach's alpha & 0.8972 & 0.9010 & 0.8053 \\
\hline
\end{tabular}

Sense of time value involves medical students' sense of the values and importance of time, which indicates their driving force and guidance in time management. Sense of time control encompasses medical students' reflections on their goal establishment, job planning, learning goals, outcome feedback, and personal time management. Therefore, sense of time control represents these students' ability to plan their time and concepts regarding time use.

Sense of time efficacy concerns students' efficacy in time management and time management behavior. The efficacy of time management involves medical students evaluating the importance of multiple tasks assigned to them at a specific time point and allocating time to each task accordingly. This includes the arrangement of their study and nonstudy time. Therefore, said efficacy involves medical students maximizing their work effectiveness through time arrangement. The efficacy of time management behavior involves medical students prioritizing critical tasks and allocating the greatest amount of time possible to them; therefore, it refers to these students considering the criticality of their tasks, allocating time to them, and prioritizing them in order accordingly. Overall, the sense of time efficacy represents medical students' effectiveness in planning and using their own time.

\section{Results of multivariate general linear model}

Between groups. The aforementioned 3 factors were confirmed through factor analysis. The analysis of variance was run on the students admitted through different approaches using a multilinear regression model. The results revealed that the students admitted through the MSP (adjusted mean $=3.924$ ), GSAT (adjusted mean $=3.729$ ), and ASTs (adjusted mean =3.802) were significantly different only in terms of the sense of time efficacy. In particular, the MSP group exhibited a significantly greater sense of time efficacy compared with the GSAT and AST groups (MSP vs. AST: $P=0.0275$; MSP vs. GSAT: $P=0.0254$; Table 3 and Fig. 1).

Table 3. Comparison of Time Management Ability Between Students Admitted to Medical School Through Different Approaches 


\begin{tabular}{|c|c|c|c|c|c|c|}
\hline \multirow[t]{2}{*}{ Approaches of admission } & \multicolumn{2}{|c|}{ Time control } & \multicolumn{2}{|c|}{ Time efficacy } & \multicolumn{2}{|c|}{ Time value } \\
\hline & Mean\# & p & Mean & $\mathbf{p}$ & Mean & $\mathbf{p}$ \\
\hline Multi-Star Project (MSP) $(n=54)$ & 3.322 & & 3.924 & & 3.805 & \\
\hline $\begin{array}{l}\text { General Scholastic Ability Test (GSAT) } \\
(n=230)\end{array}$ & 3.196 & & 3.729 & & 3.808 & \\
\hline Advanced Subjects Test (AST) $(n=106)$ & 3.203 & & 3.802 & & 3.962 & \\
\hline MSP vs AST & & 0.3760 & & $0.0275^{\star}$ & & 0.9189 \\
\hline MSP vs GSAT & & 0.2944 & & $0.0254^{*}$ & & 0.9725 \\
\hline GSAT vs AST & & 0.9261 & & 0.2149 & & 0.1531 \\
\hline
\end{tabular}

\#: Adjusted mean from model.

Within groups. The adjusted mean scores of the factors within the MSP group, in descending order, were as follows: 3.924 for sense of time efficacy, 3.799 for sense of time value, and 3.323 for sense of time control. The adjusted mean scores of the factors within the GSAT group, in descending order, were as follows: 3.803 for sense of time value, 3.730 for sense of time efficacy, and 3.199 for sense of time control. The adjusted mean scores of the factors within the AST group, in descending order, were as follows: 3.974 for sense of time value, 3.782 for sense of time efficacy, and 3.183 for sense of time control. Accordingly, the GSAT and AST groups were consistent in their sequential orders of scores for the factors (Table 4). All 3 groups exhibited significant statistical differences in each factor (all $P<0.01$ ), with the exception being between the MSP and GSAT groups in senses of time efficacy $(P<0.1041)$ and time value $(P<0.0735$; Table 4 and Fig. 2$)$.

Table 4. Comparison of Medical Students Within Each Group on Their Time Management Ability

\begin{tabular}{|lllllll|}
\hline $\begin{array}{l}\text { Time management } \\
\text { ability }\end{array}$ & \multicolumn{2}{c|}{ Multi-star project } & \multicolumn{2}{c|}{$\begin{array}{l}\text { General scholastic ability } \\
\text { test }\end{array}$} & \multicolumn{2}{c|}{$\begin{array}{l}\text { Advanced subjects } \\
\text { test }\end{array}$} \\
\cline { 2 - 4 } & Mean\# & $\mathbf{p}$ & Mean\# & $\mathbf{p}$ & Mean $^{\#}$ & $\mathbf{p}$ \\
\hline Time control & 3.323 & & 3.199 & & 3.183 & \\
\hline Time efficacy & 3.924 & & 3.730 & & 3.782 & \\
\hline Time value & 3.799 & & 3.803 & & 3.974 & \\
\hline Time control vs time efficacy & $<.0001$ & & $<.0001$ & & $<.0001$ \\
\hline Time control vs time value & $<.0001$ & & $<.0001$ & & $<.0001$ \\
\hline Time efficacy vs time value & 0.104 & & 0.074 & & 0.002 \\
\hline
\end{tabular}

\#: Adjusted means from model. 


\section{Discussion}

Medical students' time management ability varies according to their means of admission. According to the data analysis results, the between-group and within-group differences of students admitted through different means in terms of their time management ability were investigated, and the causes of these differences were also examined.

\section{Differences in time management ability between students admitted through different approaches}

The 3 primary approaches for the admission of medical students with different learning backgrounds are the MSP, GSAT, and ASTs. The 3 groups of students did not differ significantly in their senses of time control and values. However, the MSP group exhibited a significantly higher sense of time efficacy than did the GSAT and AST groups; this was because of the differences between the means of admission in their review criteria.

Students who seek admission through the MSP must have their grade point averages during the 3rd year of high school reviewed. In other words, they must maintain exceptional learning performance throughout school. Students who seek admission through the GSAT or ASTs, rather than said grade point averages, must have their one-time college entrance examination scores reviewed. ${ }^{20,21}$ Said students focus on college entrance examinations instead of high school performance, whereas those who seek admission through the MSP focus on their grades in high school, which include not only academic performance but also on-campus club and off-campus service performance.

Students with exceptional self-control are capable of following their original plans in a firm and selfdisciplined manner in the face of strong temptation, and are thus capable of attaining valuable goals in future. ${ }^{26}$ According to the factor analysis results (Table 2), sense of time efficacy refers to students' effectiveness in allocating time and arranging tasks in order according to their criticality to maximize their job performance; that is, it is their self-control ability in using time. Students with a higher sense of time efficacy are more capable of finding the optimal balance between long-term, successive academic tasks and student life. Therefore, students seeking admission though the MSP may be admitted to schools of medicine if they attain performance in the top 1-3\% in high school. Compared with the GSAT and AST groups, the MSP group exhibited a significantly higher sense of time efficacy, which also affected their learning performance at the university.

Time management ability and self-disciplined learning ability mutually affect each other. ${ }^{27}$ Students with higher self-efficacy are more capable of self-disciplined learning; self-adjustment of behaviors, emotions, and cognitions; and improving their learning performance. ${ }^{28}$ In university learning, students who fully understand the priorities of tasks, rationally assess their own learning status, set academic goals, and continuously monitor and provide feedback for their own learning progress during their plans exhibit excellent academic performance. ${ }^{29}$ Accordingly, the students of the MSP group exhibited a higher sense 
of time efficacy than did those of the GSAT and AST groups, indicating their academic performance at the university was comparable to the GSAT and AST groups even though their college entrance examination performance was less satisfactory in comparison.

\section{Differences in time management ability among students admitted through the same approach}

Within the MSP group, the students scored the highest on sense of time efficacy, followed sequentially by the senses of time value and time control. The GSAT and AST groups were consistent in their withingroup performance on the 3 factors of time management ability; specifically, the students in the 2 groups scored the highest on sense of time value, followed sequentially by the senses of time efficacy and time control (Table 4). In both these groups, sense of time value scores were significantly higher than sense of time control scores.

According to the factor analysis results (Table 2), sense of time value refers to students' senses of the value and operability of time. The sense of time control represents medical students' ideas and ability to plan and use their time, and also emphasizes planning and feedback for the initial use of time. Unlike the students in the MSP group, who possessed numerous opportunities for tests and performance, those in the GSAT and AST groups relied on the one-time college entrance examination scores as their qualification. Because the students in these 2 groups focused their time on said examinations, they exhibited a strong sense of time value.

Within all 3 groups, sense of time control was significantly lower than the other 2 factors of time management ability. The students in the MSP group, who relied on their 3-year performance in high school for university admission, required strong self-adjustment ability to find the optimal balance between high-pressure test performance and their busy daily lives. Moreover, the students' sense of time efficacy had been internalized in the GSP group, who understood the importance of self-discipline, selflearning, the formation of efficient study plans, and full comprehension of the priority of each subject in tests. ${ }^{8,29,30}$ In other words, they had learned to repeat these behaviors relevant to time efficacy without excessive thinking. Therefore, compared with time efficacy, time control was a less crucial factor of time management ability for the MSP group. Within the GSAT and AST groups, students with a satisfactory sense of time value were more likely to perform favorably in college entrance examinations than were those with favorable senses of time control. Accordingly, the students in the MSP group, who relied on long-term academic performance for university admission, emphasized time efficacy; those in the GSAT and AST groups, who relied on one-time examination scores, focused on time value.

The selection criteria for entering schools of medicine through different approaches considerably affect students' time management ability. Students with a higher sense of time efficacy are capable of systematically and effectively performing multiple tasks within an allotted time, which improves their long-term learning performance. ${ }^{2,13,28,29}$ Moreover, students' sense of time efficacy is positively associated with their self-disciplined learning. ${ }^{27}$ Because admission through the MSP emphasizes 
students' academic performance over their 3 years of high school, those who seek admission through the MSP require a higher sense of time efficacy than do those who seek admission through the GSAT or ASTs to achieve satisfactory long-term learning performance.

Because the MSP group had the highest sense of time efficacy of all 3 groups, we believe that medical students in this group would perform the most satisfactorily in their long-term medical education, which emphasizes diverse learning goals. However, this study did not investigate the relationship between time management ability and medical learning performance, which further research should focus on.

\section{Abbreviations}

MSP: Multi-Star Project

GSAT: General Scholastic Ability Test

ASTs: Advanced Subject Tests

\section{Declarations}

\section{Funding/Support:}

This study was partially supported by a research grant awarded by the Ministry of Science and Technology of Taiwan (MOST 108-2511-H-039-003 -MY2).

\section{Ethical and consent to participate:}

This study was approved by the Research Ethics Committee (\# CRREC-107-078) of China Medical University and Hospital in Taichung, Taiwan. All participants gave written informed consent before the start of the study.

Competing interests:

The authors declare that there are no conflicts of interest.

\section{Authors contributions:}

1. Haw-Yaw Shy: Conceived and designed the analysis, contributed analysis tools, performed the analysis and wrote the paper.

2. Ching-Yun Chiu: Designed the questionnaire and collected the data.

3. Ming-Wei Chiang: Designed the questionnaire and collected the data.

4. Shih-Chieh Liao: Conceived and designed the analysis, contributed the data, performed the analysis and wrote the paper. 
The authors would like to thank all the raters from the Medical School of China Medical University for participating and helping in this research. A special thank goes to Mr. Kuo-Tung Ku for the administrative assistance in the data collection process.

\section{References}

1. Macan TH, Shahani C, Dipboye RL, Phillips AP. College students' time management: Correlations with academic performance and stress. J Educ Psychol. 1990;82(4):760-8.

2. Claessens BJC, van Eerde W, Rutte CG, Roe RA. A review of the time management literature. Pers Rev. 2007;36(2):255-76.

3. Aeon B, Aguinis H. It's about time: new perspectives and insights on time management. Acad Manag Persp. 2017;31(4):309. doi:10.5465/amp.2016.0166.

4. Misra R, McKean M. College students' academic stress and its relation to their anxiety, time management, and leisure satisfaction. Am J Health Stud. 2000;16(1):41-51.

5. Koch CJ, Kleinmann M. A stitch in time saves nine: Behavioural decision-making explanations for time management problems. Eur J Work Organ Psychol. 2002;11(2):199-217. doi:10.1080/13594320244000120.

6. Trueman M, Hartley J. A comparison between the time-management skills and academic performance of mature and traditional-entry university students. High Educ. 1996;32(2):199-215. doi:10.1007/BF00138396.

7. Robbins SB, Lauver K, Le H, Davis D, Langley R, Carlstrom A. Do psychosocial and study skill factors predict college outcomes? A meta-analysis. Psychol Bull. 2004;130(2):261-88.

8. Zimmerman BJ, Greenberg D, Weinstein CE. Self-regulating academic study time: A strategy approach. In: Schunk DH, Zimmerman BJ, editors. Self-regulation of Learning and Performance: Issues and Educational Applications. Hillsdale: Erlbaum; 1994. pp. 181-99.

9. Kitsantas A, Winsler A, Huie F. Self-regulation and ability predictors of academic success during college: A predictive validity study. J Adv Acad. 2008;20(1):42-68.

10. Lynch D. Motivational beliefs and learning strategies as predictors of academic performance in college physics. Coll Stud J. 2010;44(4):920-7.

11. Young DG, Hopp JM. 2012-2013 National Survey of First-Year Seminars: Exploring High-impact Practices in the First College Year (Research Reports on College Transitions, No. 4). Columbia: University of South Carolina, National Resource Center for the First-Year Experience \& Students in Transition; 2014.

12. Prem R, Ohly S, Kubicek B, Korunka C. Thriving on challenge stressors? Exploring time pressure and learning demands as antecedents of thriving at work. J Organ Behav. 2017;38(1):108-23. doi:10.1002/job.2115.

13. Britton BK, Tesser A. Effects of time-management practices on college grades. J Educ Psychol. 1991;83(3):405-10. 
14. Price PB, Lewis EG, Loughmiller GC, Nelson DE, Murray SL, Taylor CW. Attributes of a good practicing physician. Med Educ. 1971;46(3):229-37.

15. Swan J, Carr S, Fisher C. What are the attributes of excellence in an acute practice occupational therapist? Austr Occup Ther J. 2018. https://onlinelibrary.wiley.com/doi/abs/10.1111/14401630.12519, Accessed August 31, 2020.

16. Association of American Medical Colleges. Core competencies for entering medical students. https://www.aamc.org/initiatives/admissionsinitiative/competencies. Accessed August 31, 2020.

17. Collins JP, White GR, Kennedy JA. Entry to medical school: An audit of traditional selection requirements. Med Educ. 1995;29(1):22-8.

18. Hughes P. Can we improve on how we select medical students? J R Soc Med. 2002;95(1):18-22. doi:10.1177/014107680209500106.

19. Liao SC, Hung YN, Lin CC, Lee CC, Lin CD. Using generalizability theory to construct an optimal medical student selection interview. J Med Educ. 2019;23(1):56-8.

20. College Entrance Examination Center(CEEC). 2020. University selection admission guide for general scholastic ability test. https://web.tchcvs.tc.edu.tw/resource/openfid.php?id=12087, Accessed September 25, 2020; https://www.cac.edu.tw/star109/document/109s_ken_principle.pdf, Accessed September 25, 2020.

21. College Entrance Examination Center(CEEC). 2020. University selection admission guide for advanced subjects test. https://www.uac.edu.tw/109data/109recruit.pdf, Accessed September 25, 2020.

22. Wei SL, Hou SM, Yang MC. Academic performance of National Taiwan University medical students from diversified college entrance systems. J Med Educ. 2005;9:262-71.

23. Yen CF, Liu HW, Liu KM. Comparison of academic achievements among medical students from four college entrance systems who were experiencing educational reformation. J Med Educ. 2006;10:225-31. doi:10.6145/jme.200609_10(3).0006.

24. Lee WL, Koo HW, Luoh MC, Lin MJ. Multi-channel admission and academic achievement. Taipei. 2020;48(1):31-76. doi:10.6277/TER.202003_48(1).0002.

25. Huang $X$, Zhang $Z$. The compiling of adolescence time management disposition inventory. Acta Psychol Sin. 2001;33(4):51-6.

26. Duckworth AL, Taxer JL, Eskreis-Winker L, Galla BM, Gross JJ. Self-control and academic achievement. Annu Rev Psychol. 2019;70:373-99.

27. Wolters CA, Won S, Hussain M. Examining the relations of time management and procrastination within a model of self-regulated learning. Metacogn Learn. 2017;12(3):381-99.

28. Panadero E. A review of self-regulated learning: Six models and four directions for research. Front Psychol. 2017;8:422.

29. Ramdass D, Zimmerman BJ. Developing self-regulation skills: The important role of homework. J Adv Acad. 2011;22(2):194-218. doi:10.1177/1932202x1102200202. 
30. Bembenutty H. Academic delay of gratification, self-efficacy, and time management among academically unprepared college students. Psychol Rep. 2009;104(2):613-23. doi:10.2466/pro.104.2.613-623.

\section{Figures}

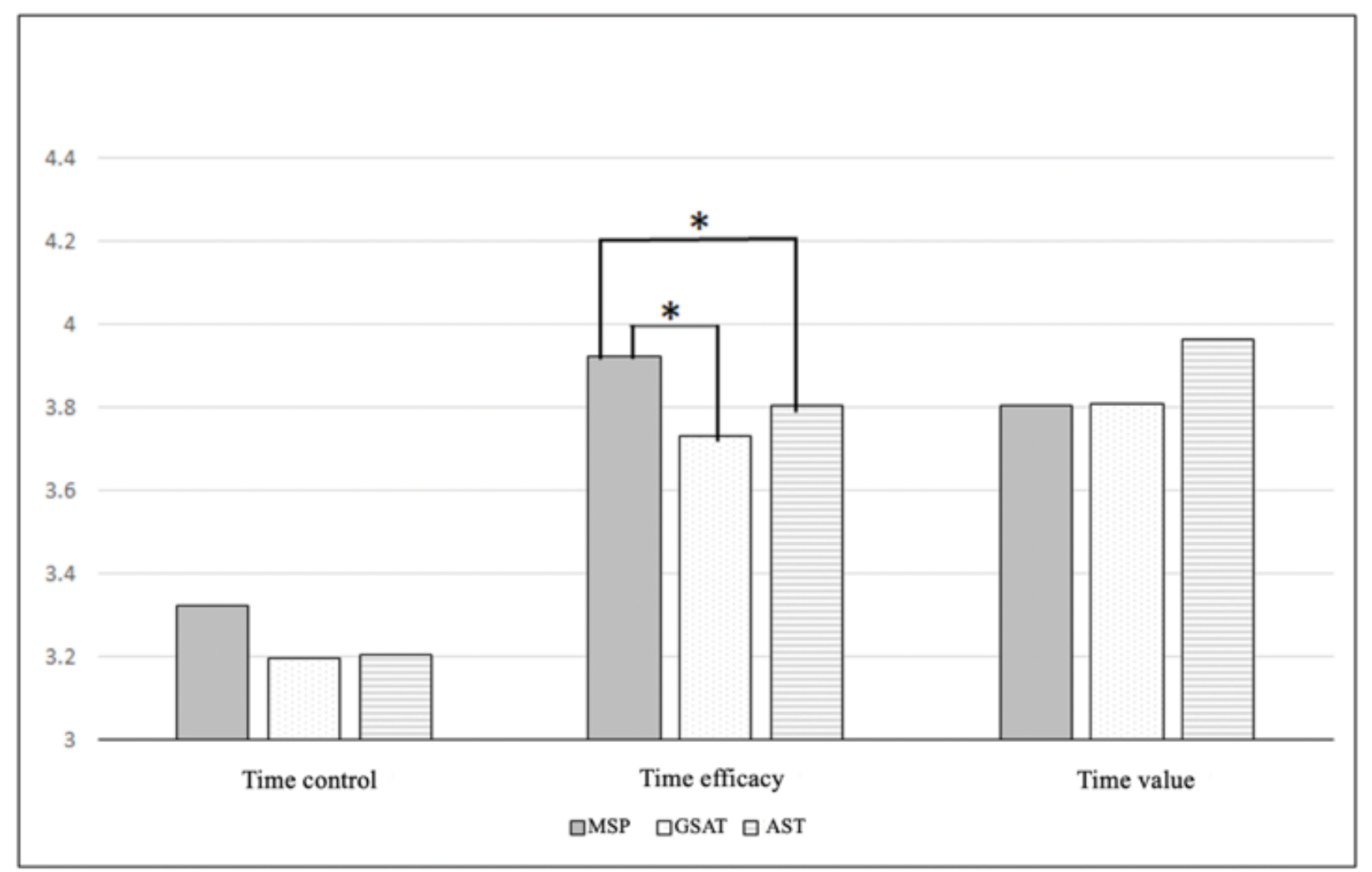

Figure 1

\section{Figure 1}

Comparison of time management ability between the 3 student groups. 


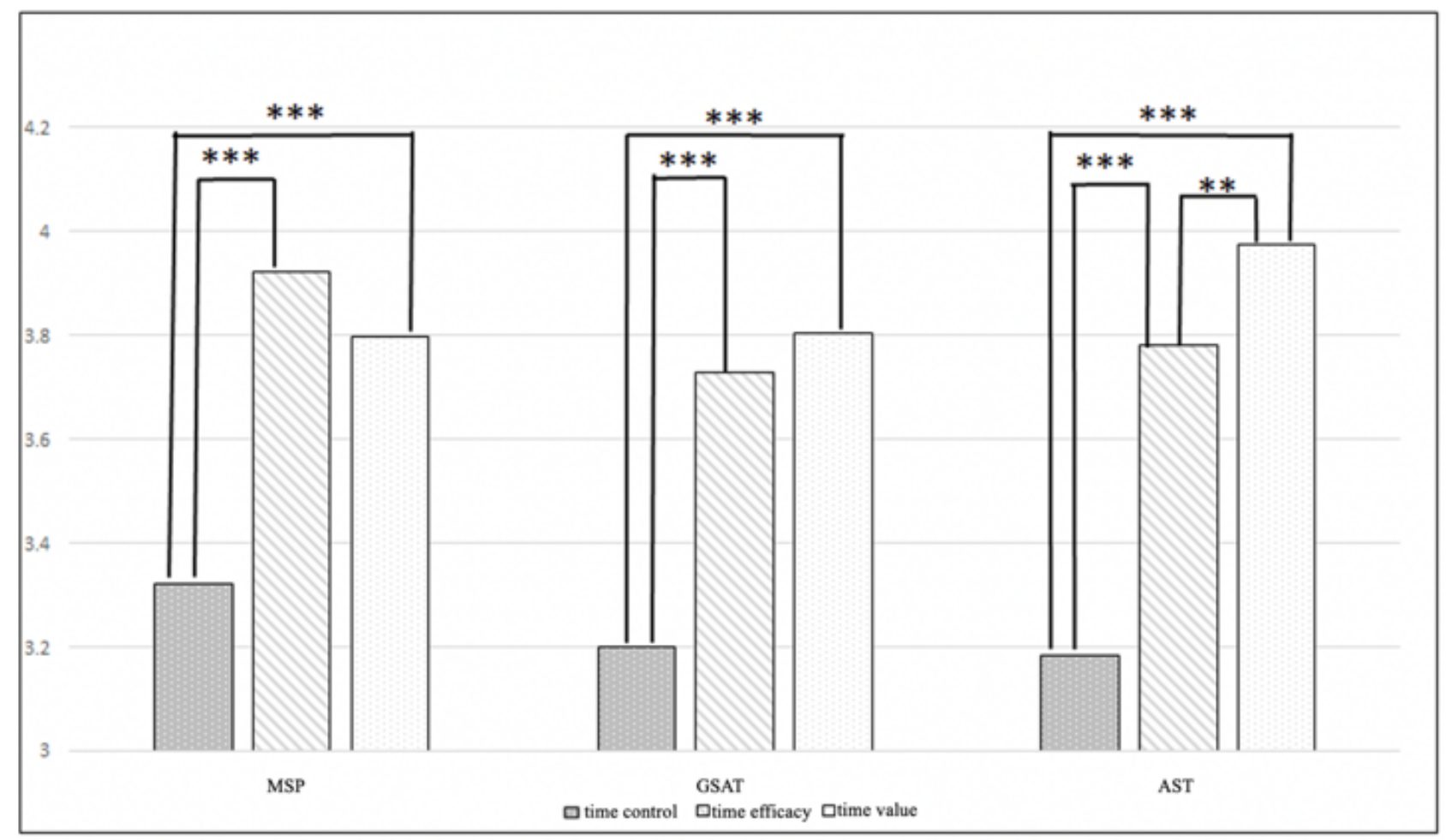

Figure 2

Figure 2

Comparison of the senses of time control, time efficacy (including sense of time control), and time value according to the generalized estimating equation method in the generalized linear model.

\section{Supplementary Files}

This is a list of supplementary files associated with this preprint. Click to download.

- Questionnaire.docx

- Rawdata.xlsx 